\title{
Occult papillary thyroid carcinoma presenting with cervical neck lymph node metastasis
}

\author{
Sunwook Han, Sunghoon Hong, Jongeun Lee, Sungyong Kim, Moo-Jun Baek \\ Department of Surgery, Soonchunhyang University Cheonan Hospital, Soonchunhyang University College of Medicine, Cheonan, Korea
}

\begin{abstract}
A 74-year-old male patient was conducted total thyroidectomy with functional neck dissection and final pathologic report confirm occult thyroid carcinoma. Although the frequency of occult thyroid cancer (OTC) has decreased owing to developments in cervical ultrasonography and improved accuracy of histological tests, rare cases are still reported. Due to the decreased frequency of OTC, a benign cervical neck lymph node mass is sometimes diagnosed, which can result in delays to more accurate diagnoses and appropriate treatment. Therefore, we report our case.
\end{abstract}

Keywords: Occult, Cervical lymphnode, Thyroid, Papillary thyroid cancer

\section{INTRODUCTION}

Papillary thyroid cancer accounts for most cases of thyroid cancer. Although the prognosis is usually good, it often causes cervical neck lymph node metastasis. Cervical neck lymph node metastases have been reported even in the absence of a primary tumor in the thyroid glands, and these cases are referred to as occult thyroid cancer (OTC). The McGraw-Hill Concise Dictionary of Modern Medicine defines OTC as "unknown primary malignancy that is symptomless, which first manifests itself as metastases or secondary-paraneoplastic phenomena" [1]. Although the frequency of OTC has decreased owing to developments in cervical ultrasonography and improved accuracy of histological tests [2], rare cases are

Received: Nov 28, 2019 Revised: Dec 21, 2019 Accepted: Dec 26, 2019 Correspondence to: Moo-Jun Baek

Division of Colon and Rectal Surgery, Department of Surgery,

Soonchunhyang University Cheonan Hospital, Soonchunhyang University

College of Medicine, 31 Suncheonhyang 6-gil, Dongnam-gu, Cheonan

31151, Korea

Tel: +82-41-570-3633, Fax: +82-41-571-0129

E-mail: ssurge@schmc.ac.kr

ORCID: Sunwook Han (https://orcid.org/0000-0002-0671-1212), Sunghoon Hong (https://orcid.org/0000-0002-3279-3581), Jongeun Lee (https://orcid.org/00000003-2938-4960), Sungyong Kim (https://orcid.org/0000-0002-2070-0915), MooJun Baek (https://orcid.org/0000-0003-3567-6687)

Copyright @ 2019 Korean Society of Surgical Oncology

This is an Open Access article distributed under the terms of the Creative Commons Attribution Non-Commercial License (http://creativecommons.org/licenses/by-nc/4.0) which permits unrestricted non-commercial use, distribution, and reproduction in any medium, provided the original work is properly cited. still reported. Due to the decreased frequency of OTC, a benign cervical neck lymph node mass is sometimes diagnosed, which can result in delays to more accurate diagnoses and appropriate treatment. Therefore, we report a case of OTC identified in a 74year-old male patient.

\section{CASE REPORT}

A 74-year-old male patient with diabetes mellitus presented to the endocrinology department. Neck Doppler ultrasonography was conducted to assess the blood vessels. A $13 \times 11 \mathrm{~mm}$-sized mass was incidentally found on the right thyroid gland that appeared benign. Additionally, a $22 \times 16 \mathrm{~mm}$-sized mass that was associated with microcalcification, an unclear hilum, and hypodensity was found at level III of the right cervical neck lymph node (Fig. 1), which appeared malignant. No other neck mass was identified, and laboratory tests including a thyroid function test and a tumor marker test, did not yield any abnormal findings. A thyroid scan was performed with technetium- $99 \mathrm{~m}\left({ }^{99 \mathrm{~m}} \mathrm{Tc}\right)$, and no other abnormalities were observed in other areas (Fig. 2). Using neck computed tomography (CT), no abnormalities other than the right thyroid mass and the right cervical neck lymph node level III mass found previously on ultrasonography were noted. A fine needle aspiration test was conducted, and the results confirmed that the right thyroid mass had nondiagnostic features. The right cervical neck lymph node mass was confirmed to be a metastatic papillocarcinoma. Total thyroidectomy with right neck functional dissection was performed, in addition to a pathological biopsy. The biop- 


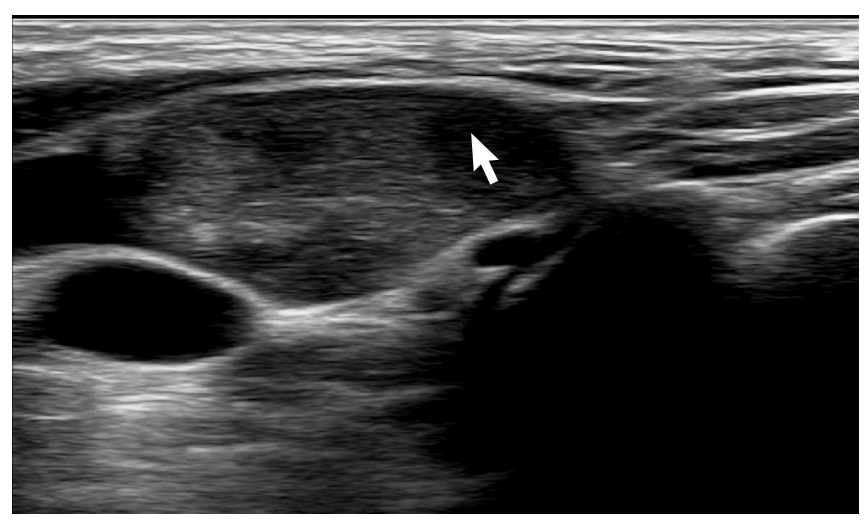

Fig. 1. Carotid Doppler ultrasonography shows incidental neck mass (22×16 mm, white arrow).

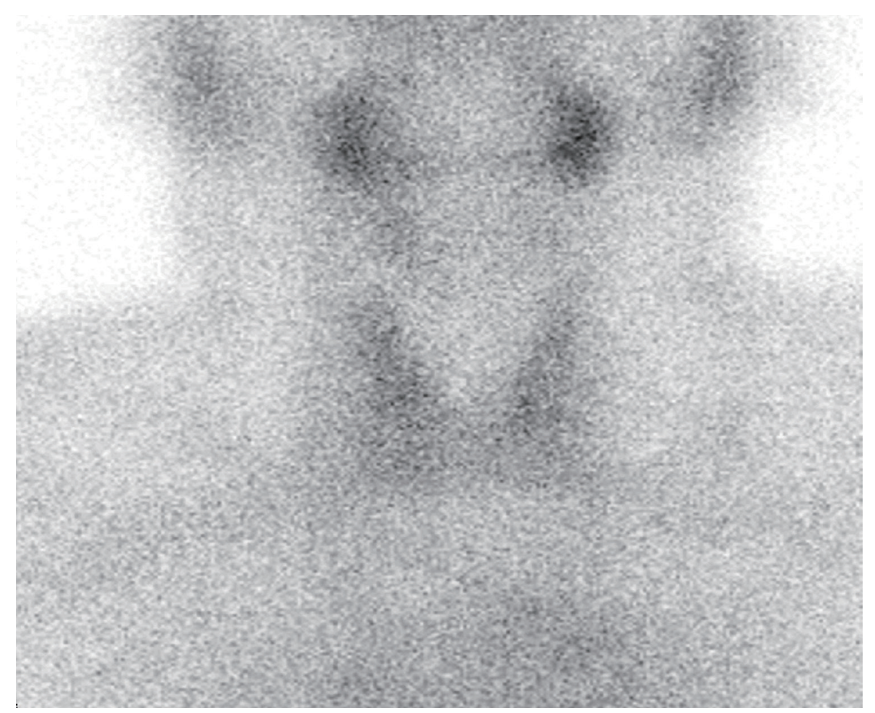

Fig. 2. Thyroid scan was performed and it showed no abnormal radiotracer uptake in other sites.

sy test results confirmed that the right thyroid mass was a hyperplastic nodule, and also confirmed metastases to seven of 21 right cervical neck lymph nodes. The largest metastatic lymph node was $18 \mathrm{~mm}$ in size (Fig. 3). The patient was discharged on postoperative day 7 , and adjuvant radioiodine ablation therapy was subsequently provided. The patient is scheduled for follow-up tests every six months to receive neck and thyroid ultrasonography and further laboratory tests.

\section{DISCUSSION}

Over the last 20 years, the use of ultrasonography thyroid screening has increased, with early diagnosis and treatment also increasing [3]. Between $70 \%$ and $80 \%$ of diagnoses have been reported to be thyroid papillocarcinomas [4]. Previously, in cases where a me-

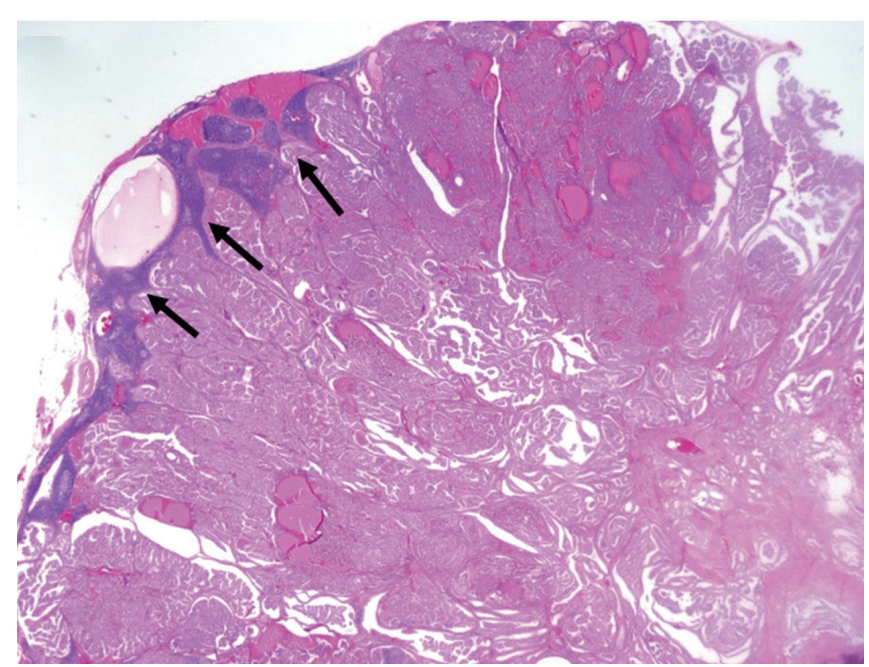

Fig. 3. Low magnification shows metastatic papillary carcinoma of lymph node (black arrows). Size of the largest metastatic focus was $18 \mathrm{~mm}\left(\mathrm{H} \& \mathrm{E}_{1} \times 1.25\right)$.

tastasis was found in other organs such as cervical neck lymph nodes, lungs, and bones, and where a primary tumor was not found in a thyroid papillocarcinoma, these cases were referred to as OTC, which had a prevalence rate of 2.2\% [5]. Improvements in cervical neck ultrasonography techniques and imaging have enabled more accurate diagnosis of malignant and benign thyroid masses up to $2 \mathrm{~mm}$ in size [6], and the prevalence of OTC has decreased with developments in pathological biopsy techniques. Within the last 10 years, the prevalence rates for OTC have been reported to $<0.2 \%$ [2].

When incidental findings of a neck mass without a thyroid primary tumor are suspected to be OTC, ultrasound-guided fine needle aspiration has been shown to be highly accurate and cost-effective [7]. If the fine needle aspiration biopsy results of a mass then confirm a metastatic lesion, then a thyroid scan and neck CT can be performed for a more detailed assessment of the thyroid glands and possible metastasis to other organs, and positron emission tomography can be considered in some cases.

If pathology test results confirm a diagnosis of OTC, surgical treatment is required. However, in some case reports, only a lobectomy or a subtotal thyroidectomy has been undertaken. However, it is highly likely that a thyroid tumor of $<2 \mathrm{~mm}$ in size may be present, which is often difficult to identify with ultrasonography, and OTC has a higher recurrence rate compared to other thyroid cancers. As such, a total thyroidectomy has been recommended, and dissection of the affected ipsilateral cervical neck lymph nodes has also been recommended [2].

Similarly, in our case, an incidental finding of a cervical neck lymph node led us to perform a fine needle aspiration, and the test 
results confirmed metastasis of the papillocarcinoma to the cervical neck lymph nodes. We used a cervical CT and thyroid scan to confirm the absence of metastasis to other organs, and a total thyroidectomy and dissection of ipsilateral cervical neck lymph nodes were performed. Final biopsy test results confirmed an absence of papillocarcinoma in the thyroid glands and indicated metastatic papillocarcinoma of several cervical neck lymph nodes.

It remains difficult to diagnose a thyroid mass $<2 \mathrm{~mm}$ in size using ultrasonography, and the size of a thyroid papillocarcinoma may be smaller than the cross-sectional diameter measured during biopsy. Therefore, although a diagnosis of OTC was made in this case, the possibility of undiagnosed thyroid cancer should also be considered.

In conclusion, although OTC has occasionally been reported in the past, its prevalence has decreased owing to improvements in ultrasonography and pathological tests. When a metastatic mass is found in cervical neck lymph nodes but without a primary tumor in the thyroid glands, fine needle aspiration is the best diagnostic tool. If the pathological biopsy test results confirm metastatic thyroid cancer, total thyroidectomy and dissection of ipsilateral cervical neck lymph nodes should be performed. In cases where the final biopsy test results confirm a diagnosis of OTC, adjuvant radioiodine ablation has been shown to lower recurrence. Since recurrence is often reported in cervical lymph nodes, continued follow-up is required.

\section{CONFLICT OF INTEREST}

No potential conflict of interest relevant to this article was reported.

\section{ACKNOWLEDGMENTS}

This work was supported by the Soonchunhyang University Research Fund.

\section{REFERENCES}

1. Boucek J, Kastner J, Skrivan J, Grosso E, Gibelli B, Giugliano G, et al. Occult thyroid carcinoma. Acta Otorhinolaryngol Ital 2009;29: 296-304.

2. Ito Y, Hirokawa M, Fukushima M, Inoue H, Yabuta T, Uruno T, et al. Occult papillary thyroid carcinoma: diagnostic and clinical implications in the era of routine ultrasonography. World J Surg 2008; 32:1955-60

3. Kilfoy BA, Zheng T, Holford TR, Han X, Ward MH, Sjodin A, et al. International patterns and trends in thyroid cancer incidence, 1973-2002. Cancer Causes Control 2009;20:525-31.

4. Pellegriti G, Frasca F, Regalbuto C, Squatrito S, Vigneri R. Worldwide increasing incidence of thyroid cancer: update on epidemiology and risk factors. J Cancer Epidemiol 2013;2013:965212.

5. Saijo H, Kitamura Y, Takenaka H, Kudo S, Yokoo K, Hirohashi Y, et al. Occult thyroid follicular carcinoma diagnosed as metastasis to the chest wall. Intern Med 2017;56:2033-7.

6. Ito Y, Amino N, Yokozawa T, Ota H, Ohshita M, Murata N, et al. Ultrasonographic evaluation of thyroid nodules in 900 patients: comparison among ultrasonographic, cytological, and histological findings. Thyroid 2007;17:1269-76.

7. Perros P, Boelaert K, Colley S, Evans C, Evans RM, Gerrard Ba G, et al. Guidelines for the management of thyroid cancer. Clin Endocrinol (Oxf) 2014;81 Suppl 1:1-122. 